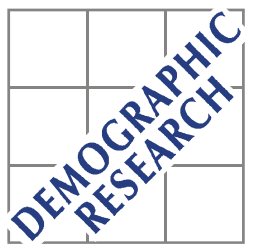

Demographic Research a free, expedited, online journal of peer-reviewed research and commentary in the population sciences published by the Max Planck Institute for Demographic Research Doberaner Strasse 114 D D-18057 Rostock · GERMANY www.demographic-research.org

DEMOGRAPHIC RESEARCH

VOLUME 6, ARTICLE 4, PAGES 67-86

PUBLISHED 20 FEBRUARY 2002

www.demographic-research.org/Volumes/Vol6/4/

DOI: $10.4054 /$ DemRes.2002.6.4

\title{
Fertility developments in Norway and Sweden since the early $1960 \mathrm{~s}$
}

\section{Gunnar Andersson}

(C) 2002 Max-Planck-Gesellschaft. 


\section{Table of Contents}

$\begin{array}{lll}1 & \text { Introduction } & 68\end{array}$

$2 \quad$ Data and methods $\quad 69$

$3 \quad$ Childbearing trends in Norway and Sweden $\quad 71$

$4 \quad$ Reflections $\quad 79$

5 Acknowledgments $\quad 82$

$\begin{array}{ll}\text { Notes } & 83\end{array}$

$\begin{array}{ll}\text { References } & 84\end{array}$ 


\title{
Fertility developments in Norway and Sweden since the early 1960s
}

\author{
Gunnar Andersson ${ }^{1}$
}

\begin{abstract}
The purpose of this paper is to give an overview of recent trends in childbearing in neighboring Norway and Sweden. We use indexes produced by applying indirect standardization to register data of these two countries in order to describe and contrast their fertility developments over the last four decades. Our indexes enable us to decompose overall fertility trends into birth-order specific components, and by combining the same kind of data from two countries we get a very accurate picture of various cross-country differences in fertility levels. We demonstrate how Swedish fertility has fluctuated relatively strongly during the whole period while Norwegian fertility has evolved more gradually, at least during the last two decades. A turnaround from decreasing to increasing levels of childbearing is evident in 1977 in both countries while a sudden shift to shorter birth intervals is specific to Sweden in the 1980s and contributed to its more spectacular increase in fertility during that decade.
\end{abstract}

Max Planck Institute for Demographic Research, Doberaner Straße 114, D-18057 Rostock, Germany.

Email: andersson@ demogr.mpg.de 


\section{Introduction}

Sweden and Norway are two neighboring countries situated in the far North of the European periphery that have a lot of characteristics in common. Their populations speak practically the same language, share the same culture, have organized their societies in very similar ways, and also have many demographic characteristics in common. The two countries have even organized their demographic data in a similar way and we will exploit this feature in the following presentation of fertility developments in these two countries over the last four decades.

As an introduction, we present aggregate trends in childbearing in Norway and Sweden as they show up in period Total Fertility Rates (TFR) over the years since 1960 (Figure 1). We notice that fertility started to decline in the two countries in the mid1960s (as was the case in many other parts of Northern and Western Europe) and that the initial level of TFR was then substantially higher in Norway than in Sweden. In the latter country, the sharpest decline occurred during the second half of the 1960s while in Norway, it mainly took place in the 1970s. In both countries, the TFR stabilized by

Figure 1: $\quad$ Total Fertility Rate for Norway and Sweden, 1960-1999.

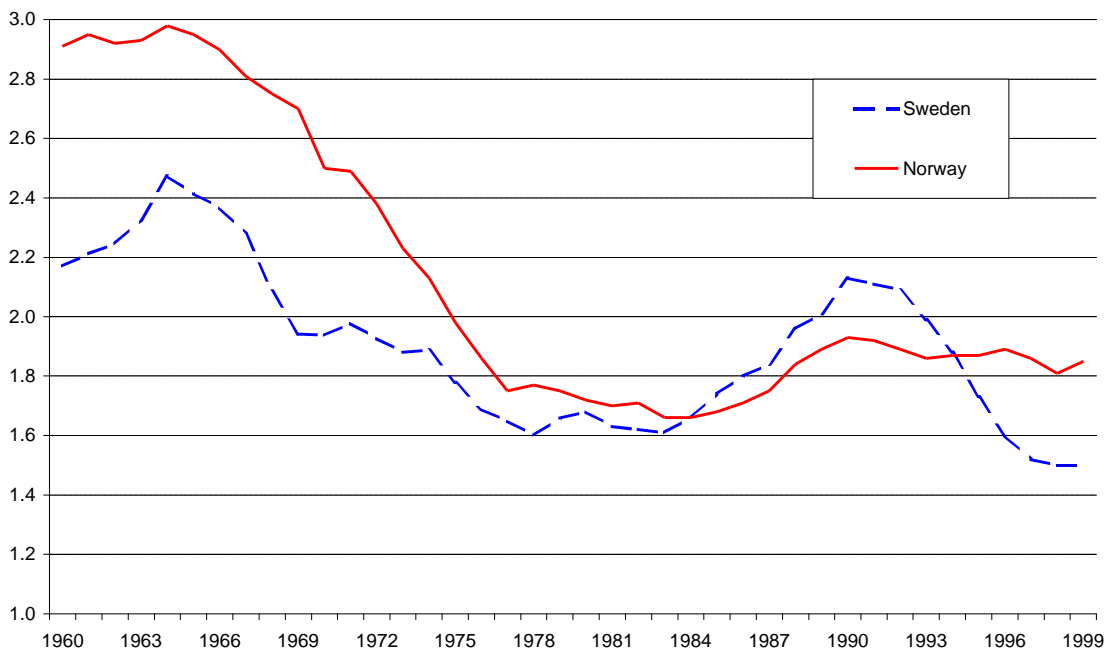


the end of the 1970s and then remained at a relatively low level (around 1.6 for Sweden and 1.7 for Norway) until the mid-1980s when both countries, in contrast to previous trends, witnessed an increase in fertility levels. The increase was stronger in Sweden than in Norway but there followed another sharp fall in fertility in Sweden during the 1990s while the TFR in Norway stabilized at a level just below 1.9 children per woman. At the end of that decade, the TFR of Sweden only reached a level of 1.5 children per woman, which by then was the lowest level ever recorded for that country, though still above that of the European Union's average of 1.4 children per woman.

Evidently, we need much more detail than a presentation of period TFR values can give if we want to get a proper picture of the childbearing developments in a country. At a minimum, we at least need to find out how the trends look for different demographic subgroups of women. In this paper, we will provide such detail by giving a presentation of trends in parity-specific childbearing, based on an efficient use of existing population-register data of Norway and Sweden. We present calendar-year indexes of parity-specific childbearing in a manner that was first suggested by Hoem (1991, 1993a) and later used for Sweden by Andersson (1999) and for Norway by Kravdal (2000). The major contribution of the present paper is that we have been able to join the data for Sweden and Norway in order to get an accurate cross-country comparison of the childbearing dynamics in these two countries. By applying modern event-history techniques to population-register data from two countries, we are able to (i) get a very accurate picture of trends in childbearing in the two countries and (ii) depict various differences in fertility levels between women in the two countries. It is our hope that our description will be useful when trying to understand, and perhaps explain, why trends have (or not have) evolved differently in Norway and Sweden. By comparing and contrasting the fertility developments of women from two very similar societies, described by exactly the same kind of data and methods, we might in some cases be in a position to derive explanations to observed changes in fertility. Various interventions in the manner of policy changes and economic turnarounds have occurred in Norway and Sweden during our study period. When an intervention occurs in one country but not in the other, we might be able to say something about the possible impact of that event on childbearing dynamics since we can control for the absence of the same intervention when looking at the development in the neighboring country.

\section{Data and methods}

The data for our calculations stem from the population-register systems of Norway and Sweden, each of which covers with a high degree of accuracy the whole population of the actual country and its vital events, and both of which are organized in practically the 
same way. Our computations are based on the number of registered live births and the corresponding exposure times of risk for various subgroups of women. These numbers are derived from the longitudinal information on the dates of each recorded birth of all women in Norway and Sweden that were born in 1935 or later (Note 1). For Sweden, the various aggregations of individual-level data have been done by Andersson (1999) and for Norway, by Kravdal (2000). For our purposes, the data sets have been joined so that we can use them in a comparative study of the childbearing dynamics in these two countries. We focus on period effects and display fertility trends in Norway and Sweden since 1960. The data for Norway cover the years up to 1997 while our updated Swedish data cover the years up to 1999.

In our analyses, we use the same estimation techniques as those used in my study on childbearing trends in Sweden (Andersson 1999), which presented relative risks of first, second, third, and fourth births for each year in the 1961-1997 period, standardized for age of woman and any youngest child of hers. Kravdal (2000) presents similar calendar-year risks of parity-specific childbearing of women in Norway in a study that otherwise focuses on various impact of unemployment on the childbearing dynamics in his country. Our estimation techniques are described in more detail by Hoem (1991). We refer to them as an "improved form of indirect standardization" (see Hoem 1993a for this terminology) (Note 2). In practice, it amounts to the estimation of proportional-hazards (intensity-regression) models, which nowadays is a standard tool for the analysis of any time-dependent data. The basic ideas behind our analyses are discussed further in Andersson (1999). For further ideas of possible fertility measures for national populations, we refer to Rallu and Toulemon (1994) and to Ortega and Kohler (2002).

In this paper, we present relative risks of childbearing for each parity progression separately, based on the number of births and the appropriate population under risk of giving birth to a child of the actual order. We present separate analyses of first births for childless women in their 20s (15-29 years) and childless women in their 30s (30 years and older) since trends and patterns in fertility differ very much for younger and older nulliparous women (Andersson 1999). We use the following set of variables in our models:

- country (Norway and Sweden).

- age of woman (ages 15-19, 20-22, 23-25, 26-29, 30-33, 34-37, and 38-44).

- calendar year (years 1960 to 1969, in five double-year groups (Note 3), and years 1970 to 1999 , in thirty single-year groups).

For women who have already given birth to at least one child, we also include a variable for the age of the youngest child, i.e. for the duration since the previous birth: 
- age of youngest child (ages 0, 1, 2, 3-4, 5-6, and 7-9 years, where age 1 corresponds to the year following the child's first birthday, etc.).

For each birth type, we present relative risks of childbearing for the interaction between "country" and "calendar year", standardized for the age of woman and any youngest child. These risks give information both on period changes in childbearing in Norway and Sweden and on various differences in levels of fertility between women in these two countries. In our presentation, we sometimes refer to our estimates as "relative risks" and sometimes as "standardized birth rates", describing differences in childbearing intensities or the propensity to give birth.

\section{Childbearing trends in Norway and Sweden}

In Figures 2 to 6, we present relative risks of childbearing by calendar year and country, with one diagram for each birth type that we cover. In each case, the risks are given relative to that of Sweden in 1977 (Note 4). Our diagrams give a very detailed picture of period changes in parity-specific childbearing over the years since 1960 and inform about differences in childbearing intensities between women in Norway and in Sweden. Figure 2 displays relative risks of entry into motherhood for childless women aged 15-29 years. It turns out that trends in first-birth rates of younger women are very similar in the two countries but that the level of first-birth fertility (of women in their 20s) is around 20 percent higher in Norway than in Sweden. In both countries, firstbirth rates decrease over time, starting from the mid-1960s in Sweden and the early 1970s in Norway. In both countries, this decline was interrupted in the 1980s, with the turnaround occurring in 1984, by increasing birth intensities in Sweden and by stabilizing birth intensities in Norway, again followed by a continued decline in firstbirth fertility at the younger ages from the beginning of the 1990s.

In a similar fashion, Figure 3 contains the standardized first-birth rates for childless women at ages 30-44. At these ages, both the trends over time and the levels of birth intensities are practically identical for women in Norway and Sweden, with fairly stable levels up to the early 1980s, followed by increasing birth intensities during the 1980s and less clear-cut trends during the 1990s. A minor decline during the 1990s in the first-birth intensities of older women in Sweden seems to have been reversed at the end of that decade. The strong increase in the 1980s reflects the tendency of a general postponement of entry into motherhood in the two countries - as it follows a previous decline at the younger ages (Figure 2). 
Figure 2: $\quad$ Standardized annual index of first-birth rates. Childless women in Norway and Sweden aged 15-29, 1960-1999.

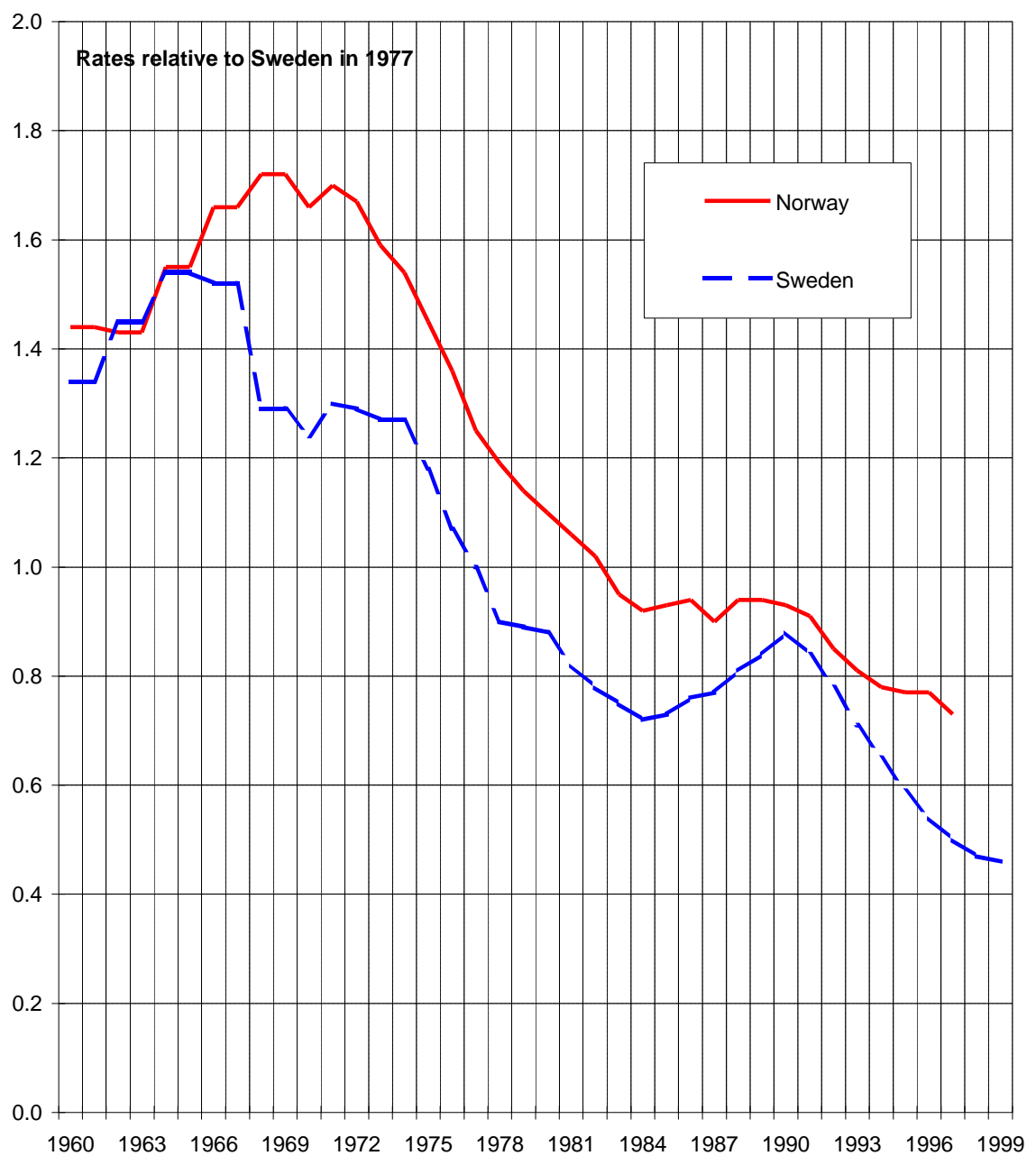


Figure 3: $\quad$ Standardized annual index of first-birth rates. Childless women in Norway and Sweden aged 30-44, 1960-1999.

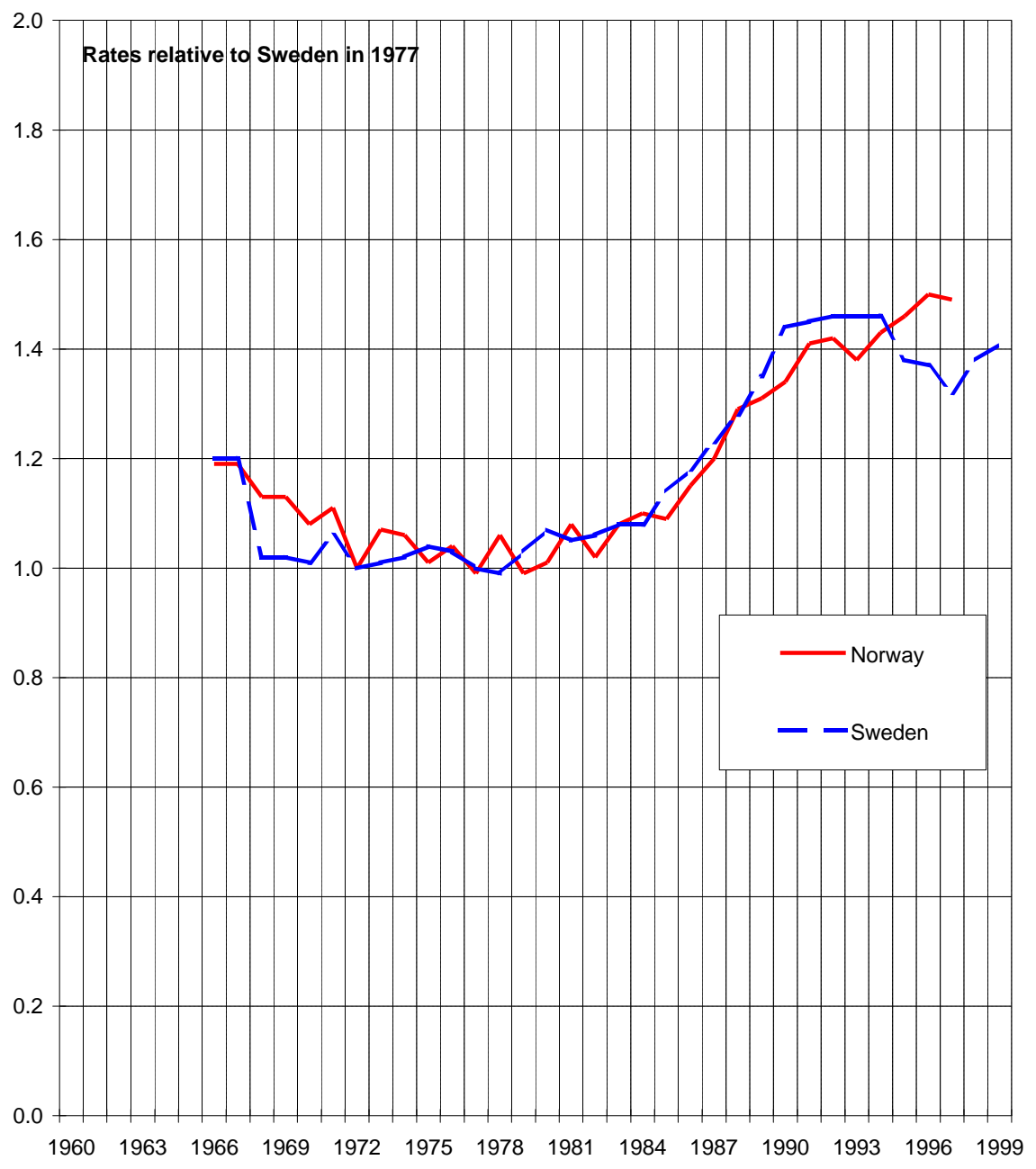


When we look at standardized second-birth rates by country and calendar year (Figure 4), we find that, conversely, changes over time are not at all similar in Norway and Sweden, at least if we focus on the last two decades of our study period. For Norway, second-birth rates decreased from the mid-1960s up to 1977 and then remained at a fairly stable level during the 1980s and the 1990s. For Sweden, by contrast, we observe a very steep increase in second-birth risks during the 1980s, followed by a fall-back in second-birth fertility between 1992 and 1997. Hoem (1993b) and Andersson (1999) demonstrated the extent to which the increase in fertility during the 1980s was related to a drastic change in the birth-spacing behavior of parents in Sweden, so that continued childbearing occurred there typically at a much faster tempo than during earlier decades. We will return to an examination of such aspects below, when we compare and contrast the changes that have occurred (or not) in the birthspacing behavior of mothers in Norway and Sweden.

In Figure 5, we proceed with a presentation of standardized third-birth rates by period and country and, finally, in Figure 6, of similar fourth-birth rates. At these higher birth orders, we again find a pronounced similarity in childbearing patterns of women in Norway and Sweden, but also important differences in how trends have evolved lately. In general, the developments of third- and fourth-birth risks are very similar to each other. For both countries and both birth orders, we observe a sharp fall in standardized birth rates from the 1960s up to 1977, when a distinct trend reversal occurred. Birth propensities increased during the 1980s. The increase was far stronger in Sweden than in Norway but in the former country the increase was subsequently followed by another sharp fall-back in higher-order childbearing in the 1990s. In Norway by contrast, thirdand fourth-birth rates leveled off in the 1990s and remained at the level they had (re)gained at the beginning of that decade. In sum, changes in higher-order childbearing were more volatile in Sweden than in Norway during the last two decades of the last century. It is noteworthy here that yet another turnaround might be under way in Swedish third- and fourth-birth rates since they have increased again during the last two years of the 1990s.

We conclude our presentation with an examination of the degree to which patterns in birth-spacing have changed in Norway and Sweden during our study period, in order to see to what extent such changes might have been related to our observed general changes in the childbearing intensities of mothers in the two countries. For this purpose, we present relative risks of childbearing by country and age of the youngest child in two selected years: 1980 and 1990. We choose these years since no important changes in birth-spacing practices occurred during the 1960s and 70s, or the 1990s in any of the two countries (not shown here). Figure 7a presents relative risks for one-child mothers while Figure $7 \mathrm{~b}$ presents the risks for two-child mothers in Norway and Sweden. (These risks are given relative to that of a mother with a youngest child aged 2 in Sweden in 
Figure 4: $\quad$ Annual index of second-birth rates. One-child mothers in Norway and Sweden, 1960-1999; standardized for age of mother and age of first child.

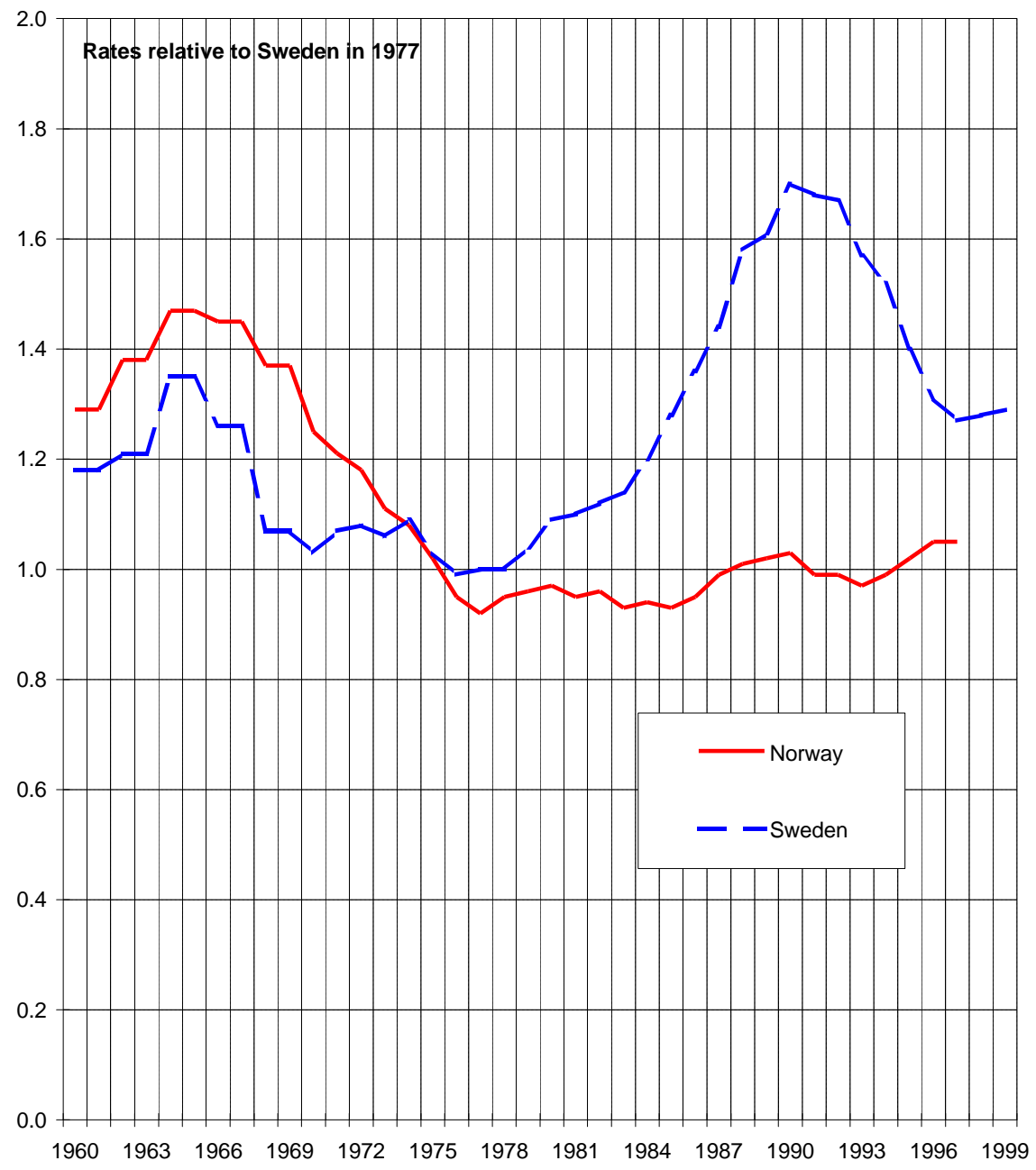


Figure 5: Annual index of third-birth rates. Two-child mothers in Norway and Sweden, 1960-1999; standardized for age of mother and age of second child.

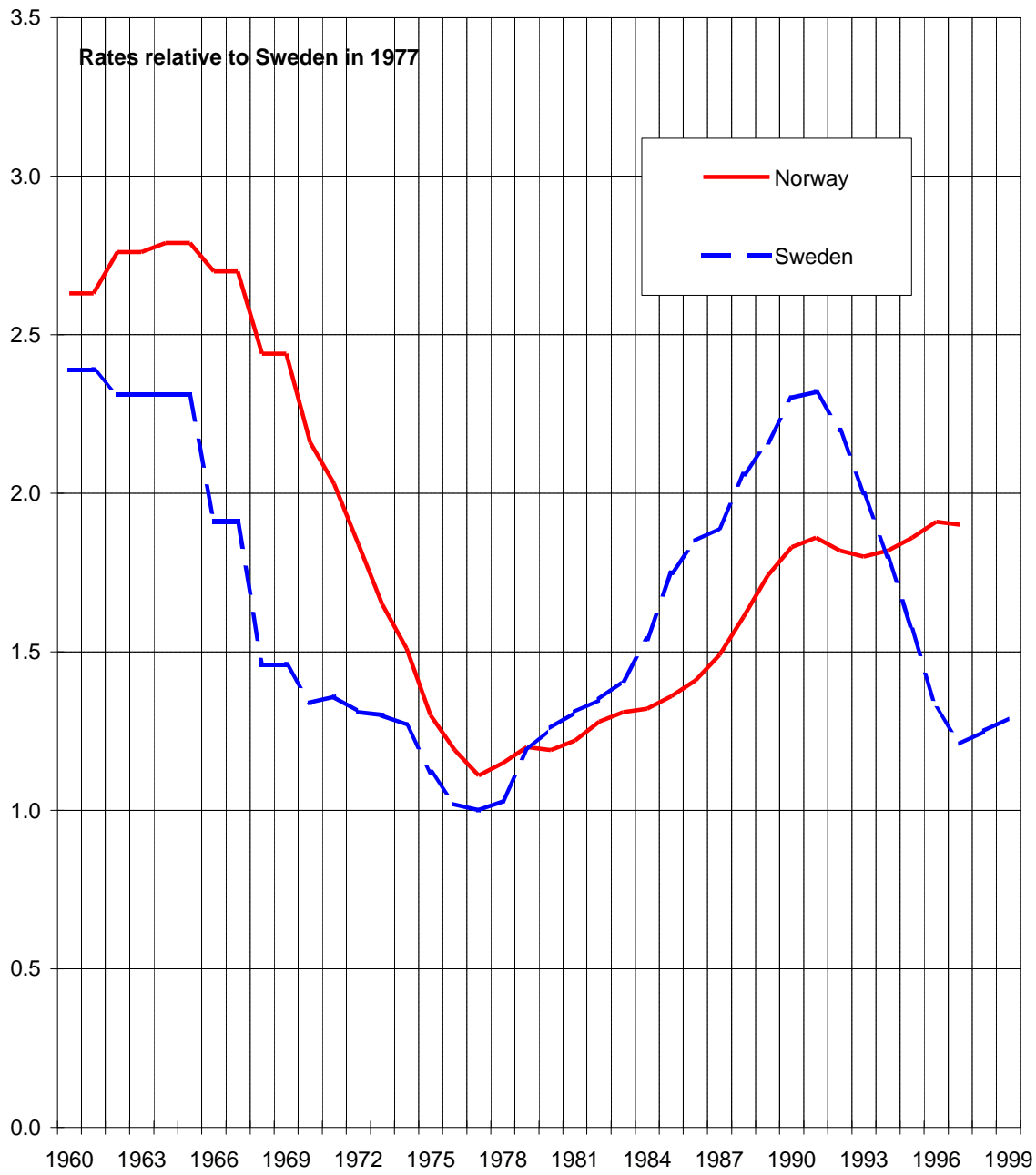


Figure 6: Annual index of fourth-birth rates. Three-child mothers in Norway and Sweden, 1960-1999; standardized for age of mother and age of third child.

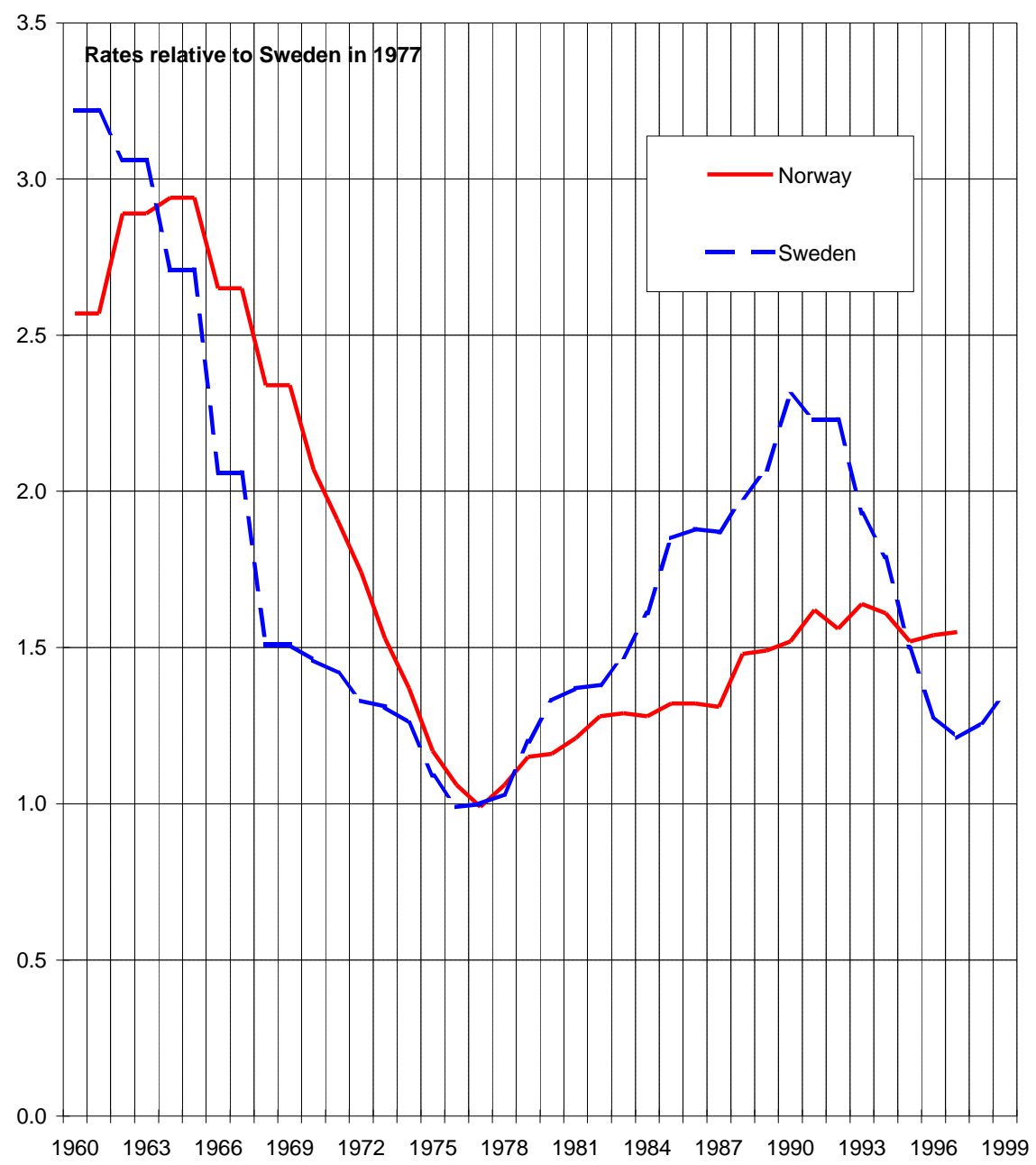


Figure 7a: Second-birth rates* by age of first child, Norway and Sweden in 1980 and in 1990; standardized for age of mother

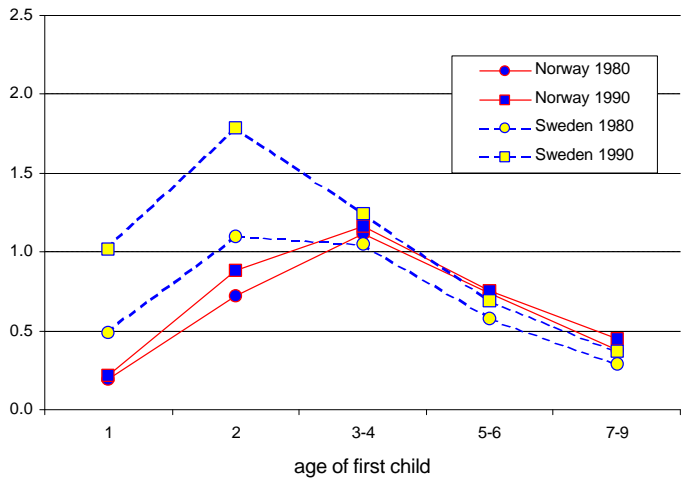

Figure 7b: Third-birth rates* by age of second child, Norway and Sweden in 1980 and in 1990; standardized for age of mother

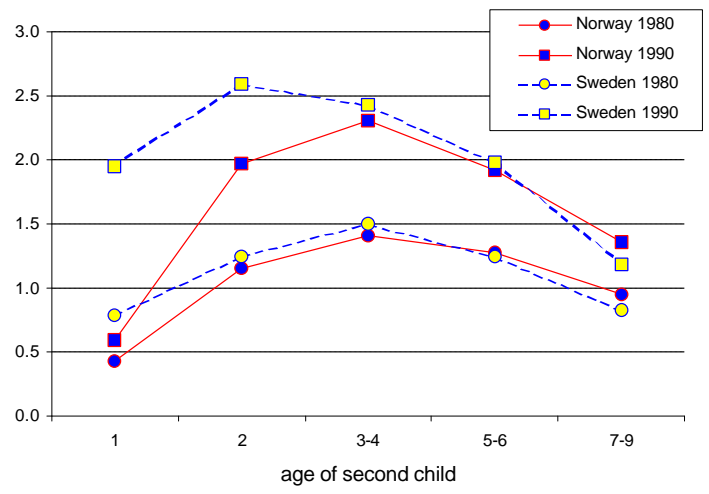

${ }^{*}$ Rates relative to that of a mother with a youngest child aged 2 years in Sweden in 1977 
1977.) Apparently, second-birth rates by age of the first child did hardly change at all in Norway during our study period. Norwegian mothers typically give birth to their second child more than three years after a first child is born and this birth-spacing practice has been fairly permanent throughout the four decades we cover. In Sweden, by contrast, women give birth to their second child more rapidly after a first child is born and here we can also observe a sharp shift between 1980 and 1990 to very elevated childbearing propensities at the shortest birth intervals. Evidently, the increase that occurred in second-birth risks during the 1980s (Figure 4) is entirely due to an increased propensity for childbearing at very short birth intervals (Figure 7a).

For third-birth risks, the picture looks slightly different. In this case, we find a substantial increase in levels of childbearing from 1980 to 1990 at practically all durations since the previous birth (Figure 7b). This holds true for both Norway and Sweden. For Sweden, however, we find an additional increase in third-birth risks at the shortest birth intervals, being super-imposed on the general increase in third-birth childbearing that occurred during the 1980s. Evidently, the additional increase in general third-birth risks that we observed for Sweden compared to Norway during the 1980s (Figure 5) was connected to this shift to a higher tempo in the childbearing of Swedish parity 2 mothers in the 1980s.

\section{Reflections}

In this paper, we have provided an overview of recent trends in childbearing in Norway and Sweden by analyzing the same type of data on the childbearing of women in both countries. By making efficient use of such data, we have been able to derive a very telling cross-country comparison of the fertility developments over the last four decades of the last century. We discovered that in many cases trends of the two countries have been highly synchronized but that they have been far more volatile in Sweden than in Norway during the last two decades. Important turning points in fertility developments are noticeable for birth risk of mothers in 1977, for birth risks of childless women in 1984, and for birth risks at all birth orders in 1990-91. These turning points appear both in Norway and Sweden. In the latter country, yet another turnaround seems to appear in 1997. This trend reversal does not show up in any description based on aggregate data, like that of a presentation of annual TFR values. We take this feature as an encouraging example of the advantages to our more refined and efficient method of analysis, which allows for the detection of changes in underlying behavior, changes that can otherwise disappear in various simultaneous changes in the composition of women (over ages of themselves and any youngest children). 
We consider it very valuable to have derived a detailed description of the childbearing developments in Norway, in the same manner as these developments already have been presented for Sweden. In a comparative perspective, we find that the description for Norway is also very illuminating when trying to understand recent fertility developments in Sweden. Norway can perhaps be seen as a case demonstrating the extent to which the childbearing trends would have developed in the neighboring country in the absence of two very strong interventions in the family sphere coming from (i) the introduction of the so called "speed premium" on childbearing (Note 5) following a policy change in the 1980s and (ii) the very sharp economic down-turn that shook Sweden in the early 1990s. Normally, it is very difficult to say anything at all about the impact on demographic behavior of various macro variables such as the different aspects of social policy and the business cycle, but we have ended up here in a slightly better position to discuss the impact of such factors. Hoem (1993b) and Andersson (1999) have already demonstrated the extent to which the introduction of the "speed premium" on childbearing in the parental-leave system of Sweden was followed by a faster tempo in childbearing there. In these cases, one could always argue that this policy intervention perhaps just strengthened a trend that was under way anyway. By using Norway as a control, we can conversely argue that this was not the case and we are also in a better position to get a picture of the magnitude of that intervention's effect.

For an elaborated discussion of the negative impact on childbearing of the economic downturn in Sweden in the early 1990s we refer to Hoem (2000) and Andersson (2000). Briefly, they demonstrate the extent to which swift increases in the number of young women with very low income explain substantial parts of the decline that then occurred in first-birth fertility. In Sweden, women with a very low income have a much lower propensity for childbearing than those who are properly established in the labor market. The Swedish parental-leave system probably also plays a role in reinforcing such a system of "pro-cyclical" fertility where the childbearing and business cycles are positively correlated with each other. In Sweden, the norm for both women and men is to get a decent level of income before thinking about having children. For the parent who intends to stay at home during the parental-leave period, there are additional incentives to receive a high income since the parental-leave benefit is based on the income earned just before childbearing. In Norway, the relationship between female labor-force participation and childbearing at the individual level is not very different from that in Sweden (see Kravdal 1992, 1994 for more information) but the economic developments have been far more stable there. Norway witnessed a minor stagnation in its economy at the beginning of the 1990s, which perhaps had an effect on the simultaneous leveling-off in childbearing intensities there, but nothing like the economic shocks that then affected Sweden. 
In our presentation, we have shown that recent fluctuations in Swedish fertility have been superimposed at least partly on similar but more stable developments in neighboring Norway. The volatile situation in Sweden has caught a lot of attention (see Hoem and Hoem 1996, 1999 and Santow and Bracher 2001, for example) but has also made it difficult to get an idea of whether there exists any underlying fertility pattern that is common to all Nordic countries. Since the 1980s, many authors have argued for the existence and importance of such a "Nordic model" of family life. In these countries, social policies have been designed to facilitate a reconciliation of male and female employment to childrearing. A considerable amount of literature argues that such a design might be decisive in creating better conditions for family building and thus results in higher fertility levels than in countries where women often have to make a decision between economic activity and family life (Berinde 1999, Bernhardt 1993, Brewster and Rindfuss 2000, Ellingsæter and Rønsen 1996, B. Hoem 1993, Joshi 1996, Lappegård 2000, Oláh 1998, Pauti 1992, Pinnelli 1995, Rindfuss and Brewster 1996, Rønsen 1998, 2001, Sundström and Stafford 1992). The present study suggests that there exist underlying similarities in childbearing patterns in Norway and Sweden, net of the fluctuations that are specific to Sweden, and that it might be relevant still to talk about a Nordic pattern of relatively high levels of childbearing.

In the case of Sweden, we perhaps even want to use Norway as a benchmark when making forecasts about the future fertility developments in that country. In many aspects, the general climate for childbearing in Sweden is now recovering from that of the gloomy period of the last decade; economic prospects now look much better than they did in the early 1990s, family policies have been restored to previous levels of generosity, and so on. In such a situation, it might not be too peculiar to expect an increase in Swedish fertility to (at least) the Norwegian levels of childbearing of the 1990s.

Although we have focused on Sweden to a far greater extent than on Norway in our discussion, we at least think that our presentation has revealed some of the advantages of a careful cross-country comparison. For the future, we hope that we will be able to expand our horizon even further while calculating similar measures of fertility for the two remaining major Nordic countries: Denmark and Finland. Evidently, an incorporation of data from these two countries into our framework will increase our scope for a meaningful discussion of the impact of various macro factors on fertility developments in the Nordic countries. Hopefully, we will then be able to take another step ahead from the state of general speculation about the impact of factors such as family policy, economic trends, and changes in contraceptive technology (Note 6 ) on observed changes in family dynamics. 


\section{Acknowledgments}

I am very grateful to Øystein Kravdal for having aggregated the Norwegian data used in this study, in a manner that they could be reconciled with my own aggregations of Swedish data, and for sharing his data set with me. In addition, I am grateful to Statistics Sweden and to Statistics Norway for having organized the raw data that we used for our aggregations. Finally, I thank Susanne Backer for comments on my language. 


\section{Notes}

1. The data for Sweden cover the childbearing histories of Swedish-born women only. The childbearing behavior of foreign-born women deviates from that of the Swedish-born in that their childbearing propensities typically are elevated immediately after immigration for example (see Andersson 2001 for further details). Nevertheless, the period trends in the childbearing risks of foreign-born women very much resemble those of their Swedish-born counterparts. In contrast, foreign-born women are included in the data set that covers the childbearing trends of women in Norway. This difference in data layout should not cause too many problems since the immigrant population of Norway is much smaller than that of Sweden.

2. We refer to our estimation as "indirect standardization" because the maximum likelihood solutions for the parameters of an intensity-regression (proportionalhazards) model have the same structure as the improved form of indirect standardization that we use, as shown by Hoem (1993a).

3. We had to make this aggregation of calendar years of the 1960s in order to reduce the total number of factor levels in our models.

4. We choose 1977 as our baseline year since it represents an important turning point in the childbearing trends of Norway and Sweden. The choice of baseline has absolutely no effect on the patterns of the curves we present: it only sets the level of our risks, i.e. the scale of the y-axis of our diagrams.

5. The "speed premium" refers to rules that were introduced in the Swedish parentalleave system and that allows parents (typically a woman) to keep an earlier (and often higher) level of income compensation during leave if a next child arrives within a fixed period of time. In 1980, this period was set to 24 months while it was extended to 30 months in 1986.

6. In this paper, we have not paid any attention to differences in the speed of the introduction of modern contraceptives in Norway and Sweden, and the possible effect that such differences might have had on childbearing developments of various subgroups of women during the 1960s. We content ourselves to note that the pill was introduced more or less at the same time in both countries in the early/mid-1960s (Bygdeman and Lindahl 1994, Østby 1989) and that the TFR of both countries subsequently started to decline in 1965 (Figure 1). 


\section{References}

Andersson, G., 1999. "Childbearing trends in Sweden 1961-1997." European Journal of Population 15: 1-24.

Andersson, G., 2000. "The impact of labor-force participation on childbearing behavior: Pro-cyclical fertility in Sweden during the 1980s and the 1990s." European Journal of Population 16: 293-333.

Andersson, G., 2001. "Childbearing patterns of foreign-born women in Sweden." MPIDR Working Paper WP 2001-011. Max Planck Institute for Demographic Research, Rostock.

Berinde, D., 1999. "Pathways to a third child in Sweden." European Journal of Population 15: 349-378.

Bernhardt, E., 1993. "Fertility and employment." European Sociological Review 9: 2542.

Brewster, K., and Rindfuss, R., 2000. "Fertility and women's employment in industrialized countries." Annual Review of Sociology 26: 271-296.

Bygdeman, M., and Lindahl, K., 1994. "Sexualupplysning och reproduktiv hälsa i Sverige under 1900-talet." Sveriges Offentliga Utredningar 1994(37). Utrikesdepartementet, Stockholm.

Ellingsæter, A.L. and Rønsen, M., 1996. "The dual strategy: motherhood and the work contract in Scandinavia." European Journal of Population 12: 239-260.

Hoem, B., 1993. "The compatibility of employment and childbearing in contemporary Sweden." Acta Sociologica 36: 101-120.

Hoem, B., 2000. "Entry into motherhood in Sweden: the influence of economic factors on the rise and fall in fertility, 1986-1997." Demographic Research [Online] 2. Available http://www.demographic-research.org/Volumes/Vol2/4.

Hoem, B., and Hoem, J.M., 1996. "Sweden's family policies and roller-coaster fertility." Jinko Mondai Kenkyu (Journal of Population Problems) 52: 1-22.

Hoem, B., and Hoem, J.M., 1999. "Fertility trends in Sweden up to 1996." Population Bulletin (United Nations) 40/41: 318-333.

Hoem, J.M., 1991. "La standardisation indirecte améliorée et son application à la divortialité en Suède (1971-1989).” Population 46: 1551-1568. 
Hoem, J.M., 1993a. "Classical demographic methods of analysis and modern eventhistory techniques." IUSSP: 22nd International Population Conference, Montreal, Canada, Volume 3: 281-291.

Hoem, J.M., 1993b. "Public policy as the fuel of fertility: effects of a policy reform on the pace of childbearing in Sweden in the 1980s." Acta Sociologica 36: 19-31.

Joshi, H., 1996. "Projections of European population decline: serious demography or false alarm?" In: Coleman, D., ed., Europe's Population in the 1990s. Oxford: Oxford University Press: pp. 222-266.

Kravdal, Ø., 1992. "The weak impact of female labour force participation on Norwegian third-birth rates." European Journal of Population 8: 247-263.

Kravdal, Ø., 1994. "The importance of economic activity, economic potential and economic resources for the timing of first births in Norway." Population Studies 48: 249-267.

Kravdal, Ø., 2000. "The impact of individual and aggregate unemployment on fertility in Norway." Unpublished paper, Department of Economics, University of Oslo.

Lappegård, T., 2000. "New fertility trends in Norway." Demographic Research [Online] 2. Available http://www.demographic-research.org/Volumes/Vol2/3.

Oláh, L.S., 1998. "Do public policies influence fertility? Evidence from Sweden and Hungary from a gender perspective." Stockholm Research Reports in Demography 130, Stockholm University Demography Unit, Stockholm.

Ortega, J.A., and Kohler, H.-P., 2002. "Measuring low fertility: Rethinking demographic methods." MPIDR Working Paper WP 2002-001. Max Planck Institute for Demographic Research, Rostock.

Pauti, A., 1992. "La politique familiale en Suède." Population 47: 961-985.

Pinnelli, A., 1995. "Women's condition, low fertility, and emerging union patterns in Europe." In: Mason, K.O., and Jensen, A.-M., eds., Gender and Family Change in Industrialized Countries. Oxford: Clarendon Press: pp. 82-101.

Rallu, J.-L., and Toulemon, L., 1994. "Period fertility measures: the construction of different indices and their application to France, 1946-89." Population: An English Selection 6: 59-94.

Rindfuss, R. and Brewster, K., 1996. "Childrearing and fertility." Population and Development Review, A Supplement to Vol. 22: 258-289. 
Rønsen, M., 1998. "Fertility and family policies - evidence from Norway and Finland." Documents 98/12, Statistics Norway, Oslo.

Rønsen, M., 2001. "Fertility and family policy in Norway - Is there a connection?" Paper for the Nordic Demographic Symposium in Tjöme, Norway, 3-5 May 2001.

Santow, G. and Bracher, M., 2001. "Deferment of the first birth and fluctuating fertility in Sweden." European Journal of Population 17: 343-363.

Sundström, M. and Stafford, F.P., 1992. "Female labour force participation, fertility and public policy in Sweden." European Journal of Population 8: 199-215.

Østby, L., 1989. "The diffusion of modern contraception in Norway and its consequences for the fertility pattern." European Journal of Population 5: 2743. 